\title{
10. The Clydesdale report: Issues of media and academic
}

responsibility

\section{ABSIRACI}

One of New Zealand's leading daily newspapers, The Dominion Post, greeted its readers on 20 May 2008 with a front page headline declaring that Pacific migrants were a 'drain on the economy'. This was reportedly the finding of a study released by Massey University economist Dr Greg Clydesdale, that 'Pacific Islanders' crime rates, poor education and low employment were creating an underclass and a drain on the economy. Pacific peoples were angered and dismayed by the Clydesdale claims, their publication on the front page of the Dominion Post, and racially prejudiced responses on talkback radio and the internet. Little evidence was provided to support the claim that they were an underclass or a drain on the economy. The Dominion Post said it published the story because of Clydesdale's status as an academic. Massey University said Clydesdale was exercising his academic freedom. This article is a case study of the controversy examining the intersecting responsibilities of academics, media and universities in response to a group vulnerable to racial stereotypes.

Keywords: balance, economy, ethics, fairness, immigration, racial stereotypes

JORIS DE BRES

Race Relations Commissioner, NZ

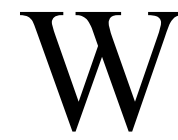

ELLINGTON'S Dominion Post greeted its readers on 20 May 2008 with a front page headline that Pacific migrants were a 'drain on the economy' (Ling, 2008a). This was according to a study released by Massey University economist Dr Greg Clydesdale (2008a), who reportedly found that 'Pacific Islanders' crime rates, poor education and low employment are creating an underclass and a drain on the economy'. 
Clydesdale was reported as warning that 'Polynesians' displayed significant and enduring underachievement, made worse by immigration.

The document containing these findings was reportedly part of a three-year study based on data from government departments. It was to be presented to a conference in Brazil in July 2008.

The Dominion Post (Figure 1) said the document, issued the previous week, found that:

- Polynesianswereless productive and less likely to contribute to economic growth;

- they had the highest unemployment in every age group, were less likely to start businesses and had lower rates of self-employment;

- they were over-represented in crime statistics, had higher rates of convictions and prosecutions, and were more likely to be victims of violent crime; and

- they were more likely to need

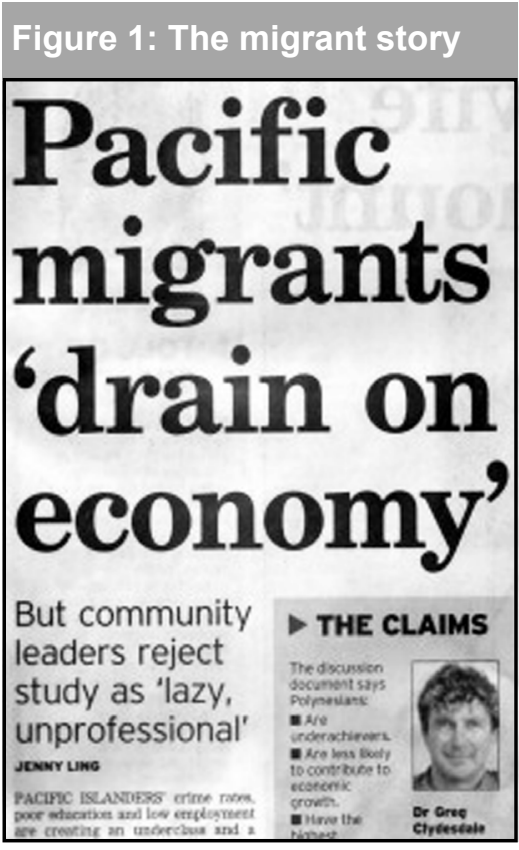

The Dominion Post, 20 May 2008. government assistance for housing and income.

Clydesdale was reported as saying: 'Of particular concern is the large Polynesian subculture whose educational achievements mean they will contribute very poorly in this regard. And because of high fertility levels and current immigration levels, New Zealand will have a significant population that can contribute little to economic growth'.

He also claimed that Pacific Island children showed low achievement in literacy on entering school and performed poorly throughout their education: 'It's scary. New Zealand's future growth depends on its ability to create new products and production processes. We're going to have a large proportion of the population without the educational requirements to create that.'

Community leaders were reported below the main headline as rejecting the study as 'lazy and unprofessional'. Quoted were Minister of Pacific Island 
Affairs, Luamanuvao Winnie Laban; Wellington Samoan Advisory Council member Fa'amatuainu Tino Pereira; and Auckland lawyer and Tongan community spokesperson Kahungunu Barron-Afeaki. They denied that Pacific peoples were an underclass and said that they made an enormous contribution.

Although Pacific Islanders had been disadvantaged in areas of health, education and employment there had been significant improvements. Students were staying in school longer, more were taking up tertiary education and there were more Pacific Islanders in high levels of the public sector. The patterns for the future were looking good.

\section{Reaction to the story}

The Dominion Post story was carried by many newspapers in the Fairfax group, and prompted news items in other newspapers, on the major television and radio networks and on talkback radio. It was reported in Australia and the Pacific and widely discussed on the internet. There were several newspaper editorials on subsequent days, television panel discussions and comments by newspaper columnists.

The initial story also prompted a flood of comments on the Fairfax group website www.stuff.co.nz . There were 216 comments on the first day, a high response rate for a news story. The vast majority accepted the findings of Clydesdale's reported study as fact, although they varied in terms of their response. Many however welcomed the findings, which, in view of the sometimes very unpleasant nature of the comments, clearly confirmed their own prejudices $^{1}$ (see opposite page).

The story was received with anger and dismay by the Pacific community. National Pacific Radio Network station NiuFM received a flood of calls and Pacific journalists in particular pursued the story with a degree of disbelief at the claims being made and the support being expressed for them in some quarters. New Zealand Herald columnist Tapu Misa and Television New Zealand's Pacific correspondent Barbara Dreaver were among those who spoke out strongly.

Television New Zealand's Tagata Pasifika, New Zealand's only mainstream Pacific television news programme, devoted a significant part of its weekly programme to the subject the following week. A lengthy telephone interview with Clydesdale by then Pacific Islands Media Association's chairman Aaron Taouma was widely circulated on the internet and used in news 


\section{Some responses to the Dominion Post story on the Fairfax website}

'Finally an article published to back up what we're all thinking.'

'I didn't need a study to state the obvious. A drive through South Auckland should do the trick.'

'Dr Clydesdale, thank you for making the study public! People need to hear this more as, even though the majority of people in NZ see it as a common sense, having someone like you speaking up-l applaud you!'

'Laban provides two examples of people who have succeeded in life.

Fair play, good stories, warm fluffies n' all but how on earth can she argue with cold, hard facts? It is not a racist jibe, nor is it a witch-hunt... Winnie my dear, it's just facts... the old adage that "stats don't lie" could never be truer.'

'I completely agree with this report. Polynesians have been dragging our society down for years. They're the main contributor to our high unemployment rates and are the leaders in crime in this country. This isn't racism, it's the bloody truth.'

'Sad-but very, very true. Full marks to Greg Clydesdale for having the courage to publish the findings of his three years study.'

'The only thing I find incredible, is that it took a university professor three years, no doubt at considerable taxpayers' expense, to come to the same conclusions that have been painfully evident to the majority of New Zealanders for the last 40 years!'

'Wait for the screams of racism. Good on you Greg for speaking up, you are only reporting what the data shows and the instant response of "lazy" shows it's hitting home.'

'We need more studies like this published by brave academics. The problem is that too many narrow minded people criticise academics who publish findings contrary to the status quo... I personally am not surprised by the results.'

'The majority of those on the benefit are Pacific Islanders. How can people not realise this and instead ignore it? Do people read the newspaper? Have people noticed that most of the crimes committed are by Pacific Islanders? Read the wanted column and you will notice that the majority of those with mug shots are Pacific Islanders.'

'Stop being ignorant people. We all know that Pacific Islanders are the reason this country is going downhill. It's apparent that people just ignore the facts. Why do you think TAX is so high in NZ? And where do you think our taxes go? To the government? NO! Our taxes are used to pay those people on the benefit. I'm not saying all Pacific Islanders are on the benefit, but a majority of them are.' 


\section{Daring to dream big dreams for her children}

'My mum is an islander who came to this country with no formal qualifications. She has worked as a cleaner and an industrial sewer. She is a warm loving mother and grandmother who's never broken the law. She is hard working, clever, beautiful and well spoken and I am incredibly proud of her.

According to Dr Clydesdale's report, my mum is not the sort of immigrant wanted in this country because economically she's not worth a lot.

But in other ways she's worth everything decent.

Like other islanders she has dared to dream big dreams for her kids. Given that Pacific Islanders like my mother have invested so much of their hopes and dreams in this country it is hardly surprising that Greg Clydesdale's report was greeted with an outpouring of emotion from the Pacific community."

—Barbara Dreaver, TVNZ Pacific affairs reporter ${ }^{2}$

broadcasts. Radio New Zealand's Pacific affairs reporter Richard Pamatatau also pursued the story. (See Television NZ's Barbara Dreaver's response on p. 153)

The Dominion Post reported briefly the next day (Pacific community 'gutted by study', 2008) that some in the community were 'gutted' by the study but that the author was unrepentant. It said the document had drawn a scathing response from Pacific Island leaders and quoted one more, a Samoan youth leader in Napier, who said: 'We have some really good Pacific role models and some really good achievers. The Pacific community work hard. They pull their weight in the economy of New Zealand. Reading this article has really gutted us.'

Clydesdale was reported in the same story as having been inundated with calls and also an email from an angry Wellington student and disapproval from a fellow academic, but most had been supportive. He said: 'The vast majority of New Zealanders recognise what I am saying but they are scared to stand up because the media clamp down on them and call them racist.' He was adamant that New Zealanders needed to debate the costs of immigration and population growth, which he described as an 'intellectually bankrupt area'. He said that intensified housing would lead to a society in which children no longer played in big backyards and climbed trees.

There was no further report in the Dominion Post until May 26, when there was a story about the Race Relations Commissioner's review. On 
May 28, under the heading of 'extremes of political correctness', the newspaper negatively editorialised about the decision to conduct a review. It defended its publication of the story on the grounds that it was 'based on research-part of a three-year study' by a Massey University economist and cited academic and press freedom. The following day (May 29) the paper reported criticism of the report by academics and published an article by the Chief Executive of the Ministry of Pacific Island Affairs challenging Clydesdale's findings. Further news items followed on June 6 and 7 about the effect on the reputation of Massey University, academic freedom and professional standards. On June 24 the newspaper also reported a meeting of Pacific community representatives held in Porirua, including the announcement that organisers of the Brazil conference had rejected Clydesdale's paper because he had breached conference rules by pre-publishing it.

In August, the paper published a full page feature which revisited the controversy (Dominion Post, 9 August 2008). It noted:

Dr Clydesdale claimed Pacific people were an 'underclass', underachievers, less likely to contribute to economic growth and at the bottom of various indicators of success, including education and income. He used seven-year-old data, though two-year-old figures were available, ignored extensive and sophisticated research in this area, shunned peer review or academic debate about his work, and publicised his findings with self-written press releases which he emailed, along with a discussion paper, to media outlets. The paper was riddled with grammatical errors and sloppy referencing.

The Dominion Post published his findings alongside three comments from Pacific leaders dismissing them. While talkback and website comments suggested he had struck a chord, criticism of the research, and the prominence this newspaper gave it, was widespread, particularly from the Pacific and academic communities.

The editor of the Dominion Post, Tim Pankhurst, was quoted in the article as saying it was lines such as 'three year study' and the title 'Massey University economist' that led the newspaper to conclude that Clydesdale was credible. The feature article set the record straight.

\section{On reflection}

The original coverage of Clydesdale's report in the Dominion Post turned out to contain some inaccuracies, to be based on some unfounded 
assumptions and to leave some important questions unanswered. These were:

1. The term 'drain on the economy', used in quotation marks in the headline and widely used in other media was not in fact a quote from Dr Clydesdale. The newspaper acknowledged this in a clarification published on June 20, following a complaint from Massey University.

2. Dr Clydesdale was referred to as an economist from Massey University and the assumption was that he was therefore an expert on the subject of his report. However, he had not published any papers in academic publications on either immigration or Pacific peoples. His area of specialisation was in entrepreneurship, economic growth and creativity. There were acknowledged immigration and Pacific specialists at Massey University and elsewhere with whom the report and Clydesdale's credentials in the field might have been checked.

3. Dr Clydesdale's discussion paper was described as 'the document' and as 'part of a three year study called "Growing Pains, Evaluations and the Cost of Human Capital"'. The reader might take from this that there was a substantial or formal research project behind the paper. In fact, the 'three year study' might more accurately be described as Clydesdale having done some study of reports over the past three years. The result was two conference papers, one on business migrants and the other on immigration policy, but very little on Pacific peoples. The first conference paper was presented at a conference in Cardiff in 2007 and the other was submitted at the end of 2007 for the Brazil conference. The 'document' referred to by the Dominion Post appears to have been a version of the Brazil conference paper submitted in 2007 with the new title 'Discussion Paper: New Zealand Immigration Policy' and the old title of the conference paper remaining on the inside page. The title was actually 'Growing Pains: The valuation and cost of human capital'.

4. The Dominion Post described the 'document' as having been 'issued last week'. The newspaper, like other media outlets, did receive it as an email attachment accompanied by two press releases from Clydesdale. However, it was not a new paper, it was not new research, and it had not been published in an academic context. Clydesdale had similarly released his research on a number of occasions in 2007. On February 28, The Press in Christchurch reported 'new research 
by a Massey University economist', and quoted Clydesdale as saying: 'A large number of our immigrants are humanitarian (cases) and there are a large number of Polynesians. The Polynesian immigrants are increasing the contestability of government social services.'

5. The Press again reported 'new research' by Clydesdale on April 7, finding that current immigration policies were 'hitting Kiwi families in the pocket and the number of new immigrants should be slashed'. The Dominion Post on April 17 also reported that Clydesdale had 'made public the results of a study on the economic effects of immigration'. On July 10, the New Zealand Herald reported Clydesdale as a Massey University academic saying that migration policies were bad for the economy and that immigration numbers should be cut in the family sponsorship and humanitarian categories. On September 5 the Dominion Post published an opinion piece by Dr Clydesdale, referring to these earlier media reports and saying that Māori concerns about migrants (particularly those from the Pacific) were justified. He wrote that Māori were becoming an intergenerational underclass because home ownership was moving out of their reach as a result of immigration and that Pacific Island migrants were competing with them for resources and jobs.

6. The discussion paper sent to media outlets was not mainly about Pacific Island migration at all-it was about immigration policy generally and the perceived negative impact of immigration on economic growth. A second press release from Clydesdale accompanying the document was headed 'Slow growing economy linked to immigration' and summarised the wider scope of his paper. ${ }^{3}$ In a 20-page discussion paper, the section on Pacific migrants consisted of five paragraphs and a table and the press release reproduced much of it word for word. It contained few details of Pacific peoples' social and economic situation and contribution to economic growth and only some general statements that various indicators relating to Pacific peoples were higher or lower compared to other groups.

7. Dr Clydesdale's research project was described as being 'based on government data from the Economic Development Ministry, Labour Department and Pacific Island Affairs Ministry'. No comments from these agencies were reported, although on the following day two of them were reported as having asked the Dominion Post for a copy of the discussion paper.

8. It subsequently transpired that the government reports referred to were mostly old reports based on the 2001 Census and earlier data. More recent 
government reports including the 2006 Census and the 2006-7 migration trends report were not used. The data used was described by both academics and government departments as out of date and therefore misleading.

9. The assumption was that Dr Clydesdale's research had been published or at least that the discussion paper, having been released, was available. In fact, the document was not publicly available and the only way of obtaining it was either by seeking a copy from the Dominion Post reporter or from Clydesdale himself. Its unavailability made it difficult for people to judge the report for themselves and to respond to it in an informed manner.

These issues were for the most part addressed in reports and articles in the Dominion Post in subsequent weeks, and comprehensively in a feature article in August, but the newspaper's very limited followup in the first week did not do so.

\section{The release of the discussion paper}

It is reasonable for the public to assume that academics employed by reputable institutions such as Massey University will observe professional and ethical standards in conducting and publishing their research. Massey is one of New Zealand's largest universities and has highly qualified staff in a wide variety of fields. The brand 'Massey University academic' therefore carries with it values not just of academic freedom (acting as a critic and conscience of society) but also of academic responsibility (integrity, professionalism and ethical standards). The public should be able to have confidence that when a piece of work is published, it has met these basic standards, and that the author(s) will be willing to debate the research and will in turn take criticism seriously.

The question therefore arises as to whether the contents of Clydesdale's paper, the method of its release and his subsequent comments about it met the requisite academic standards in light of the following:

1. He had on several occasions in the past 18 months represented findings of his research to the media as 'new research', yet no research had been published and largely the same information had been released on each occasion. His newly released discussion paper was actually a forthcoming conference paper that he had submitted to the conference organisers the previous year. The various releases of his research findings had tended to be by email to the media in response to public statements or controversies, with reference to new research giving weight and newsworthiness to his views. ${ }^{4}$ 
2. Two peer reviews of his paper-by associate professor Paul Hanson of the Department of Economics at Otago University and Dr Paul Callister of the Institute of Policy Studies at Victoria University-were commissioned by the Ministry of Pacific Island Affairs. A third review was independently produced by professor Cluny McPherson of Massey University. Points made by the reviewers included that:

- the paper was clearly only a draft and had spelling mistakes and poor referencing;

- 2001 Census data were used despite the availability of 2006 Census data;

- definitions and terms were problematic (e.g. underclass and confusion between ethnicity, country of birth and culture);

- important contextualising information was omitted;

- too few variables were considered in the analysis;

- assumptions about productivity were problematic;

- more recent sources and studies had not been used;

- the goal of immigration was too narrowly defined; and

- the analysis was sloppy and errors and flaws rendered the discussion highly problematic.

Dr Clydesdale claimed that the peer reviewers had not reviewed the correct version of the paper as it was a discussion document only. He told the Dominion Post that 'they came to the conclusion that it lacked academic rigour-I could have told them that'(Ling, 2008c). He said it was the academic version that had been peer-reviewed by the organisers of the Brazil conference. In fact the two papers appear to have been one and the same except for the title page. The claim that there was more than one version of the document, however, made it difficult to engage in a discussion of it.

3. His public defence of the discussion paper included that it was based on government reports and government data. He told the NZ Press Association: 'I'm not saying anything new. This is government data.'(quoted on NZ Herald website, 20 May 2008, www.nzherald.co.nz ). Although he was making policy recommendations to halt Pacific migration based on his research, he did not indicate that the government data were largely from the 2001 Census and earlier reports and that his findings had not been updated in the light of the 2006 Census and more recent reports.

4. In the event, the conference organisers in Brazil asked for the paper to 
be withdrawn because he had breached the conference rules about not presenting previously published material. The paper had been publicised in the media and had become available on the internet.

\section{Massey University's response}

Massey University's public response to the controversy focused mainly on a defence of academic freedom. The head of the university's College of Business, professor Lawrence Rose, said in the Dominion Post on 6 June (Ling, 2008c) that he did not endorse the report but stood by his colleague's right - and that of all researchers - to take up the issues and put them in the public domain to provide debate. 'In the process of that debate ideas are fine-tuned and improved and might even win the day or change opinion a bit. That is healthy for any democracy. Ideas that don't have merit are pushed to one side and forgotten about.' He said he was pleased with the vigorous debate around the report but 'it is not an endorsement of the paper'. He acknowledged that it was a sensitive issue and that some people had been hurt by the process.

Acting communications director James Gardiner cited Dr Clydesdale's right to academic freedom under the Education Act. He was reported as saying that the Act essentially gave academics carte blanche with their research, although they were expected to act in a scholarly and professional manner: 'Universities are not about gagging their staff and they are not about saying you can only do research into approved areas.' He said there were codes of ethics for how staff conducted research but no guidelines on publishing work. Massey had concerns with the way Clydesdale had made his work public. 'Ideally, the documents would be proof-read and they'll be professionally written' (Chalmers \& Ling, 2008b).

The university's only press release on the matter (and the only official comment on its website) came from the acting director Pasifika, Sione Tu'itahi (2008). He expressed concern about the negative impact of the discussion paper on the Pacific community. He said it failed to recognise the wider contribution of Pacific people. He contrasted this with the university's Pasifika@Massey strategy which reflected 'the official position of Massey University and its commitment to the socio-economic wellbeing of Pasifika peoples.' He said that Pasifika@Massey aimed 'to build on strengths, achievements, potentials and aspirations of Pasifika peoples' and focused on 'working with Pasifika 
peoples to find solutions rather than accentuating problems and approaches that are based on deficit models'.

'By measuring people as economic units, Dr Clydesdale has presented a limited view of the positive role and contribution of Pacific Islanders to New Zealand society.' While he respected academic freedom, the report reflected 'just one way, an economic analysis and interpretation of multiple facts, largely systemic, that contribute to the socio-economic status of Pasifika peoples. Massey's Pasifika Strategy, on the other hand,is about working with fellow human beings to realise their full potential.'

There was strong criticism of the university by the Chief Executive of the Ministry of Pacific Island Affairs, Dr Colin Tukuitonga, who argued that Clydesdale's discussion paper should have been assessed by another academic before release. 'Academic freedom does not mean you're free to be reckless. If Massey is saying it's fine for its academics to put out garbage-I just find that staggering.' He said that the two peer reviews commissioned by the ministry found that the data used was outdated. 'The problem now, though, is [that] in the minds of people this is fact, even though there are serious flaws in regards to the analysis, presentation of the data and the source of information' (Chalmers \& Ling, 2008).

A number of complaints were made to Massey University about the academic standard of Clydesdale's paper and the method of its release. (See the panel on Academic freedom on p. 161.) These included a complaint from the university's own Pacific People's Consultative Group, the Chief Executive of the Ministry of Pacific Island Affairs and Auckland barrister and Human Rights Review Tribunal member Satiu Simativa Perese. The university did not say anything publicly about the complaints and what it was doing about them. It appeared to see this as a matter solely between employer and employee, not between the university and the public. While it would have been inappropriate for the university to comment on the substance of the complaints before completing its inquiries, that should not have prevented it from outlining the statutory constraints on academic freedom, its obligation to uphold academic standards and to be accountable to the public and the processes available for dealing with complaints. It would not have compromised the process to state publicly that complaints had been received and how they would be dealt with. 


\section{Academic freedom and autonomy of academic institutions}

The Education Act specifically provides for academic freedom, ${ }^{5}$ stating at Section 161 that it is the intention of Parliament that academic freedom and the autonomy of academic institutions are to be preserved and enhanced.

The definition of academic freedom includes:

- The freedom of academic staff and students, within the law, to question and test received wisdom, to put forward new ideas and to state controversial or unpopular opinions;

- The freedom of academic staff and students to engage in research.

The Act further provides that in exercising their academic freedom and autonomy, institutions shall act in a manner that is consistent with:

- The need for the maintenance by institutions of the highest ethical standards and the need to permit public scrutiny to ensure the maintenance of those standards; and

- The need for accountability by institutions and the proper use by institutions of resources allocated to them.'

In order to fulfil its obligations under this section, Massey University has a Code of Ethical Conduct for Research, Teaching and Evaluations Involving Human Participants. ${ }^{6}$ The Code applies to 'all research involving either the participation of humans or where the research impacts on individuals, groups or communities' and is 'an expression of the basic human rights of respect for persons, autonomy, privacy and justice'.

Ethical principles set out in the code include respect for persons, minimisation of harm to participants, researchers, institutions and groups, social and cultural sensitivity to the age, gender, culture, religion, social class of the participants and justice. Section 3, on application of the principles, notes that:

- Publication of research results has the potential to harm groups, communities and institutions. Researchers must be aware of this in writing up results.

- While Massey University is committed to the concept of academic freedom in research, the risks involved in research must be assessed and managed appropriately in order to protect the reputation of the institution.

- Researchers are under an obligation to anticipate the consequences of any study on ethnic populations or cultural groups.

The university's policy on staff conduct affirms academic freedom but notes that it is 'circumscribed by the law' and 'by the ethics of a staff member's profession'. The principal standards of conduct include an expectation that a staff member will 'maintain satisfactory standards of work and a standard of personal conduct appropriate to his/her responsibilities' and 'ensure his/her actions and behaviour are always ethical and professional'. 


\section{Dr Clydesdale's findings}

The surprising fact, given the extent of the controversy surrounding the release of Clydesdale's discussion paper, is that his discussion of Pacific peoples largely consisted of five consecutive paragraphs in a 20-page discussion paper and one small table compiled from a 2002 report. (As noted elsewhere, there are four further paragraphs relating largely to situations in other countries, a paragraph in another section of the paper reiterating some of the earlier comments, and one paragraph also elsewhere about the carbon footprint of migrants including those from the Pacific). Clydesdale reproduced the five consecutive paragraphs above almost in full and word for word in his press release(as follows), although the possibility in the paper that immigration may be fuelling an underclass has in the press release become a fact:

\section{Polynesian immigration fuels underclass}

Polynesians are becoming an under-class in New Zealand society, and immigration is only making the problem bigger, according to a discussion paper released by Dr Greg Clydesdale of Massey University.

'Much of this depends on your definition of underclass, but as an ethnic group, Polynesians display significant and enduring underachievement.'

The government's own data shows that of all immigrant groups entering New Zealand, Pacific Islanders have less productivity and are less likely to contribute to economic growth. They are much less likely to start enterprises with lower rates of employers and self-employed. They are the highest unemployed in every age group. They also earn disproportionately lower incomes.

In theory, bringing in un-skilled workers should not necessarily dampen economic growth if they fill low-skilled employment gaps. It allows companies to keep costs down, but provides the basis of a class-based economy with locals holding the higher paid management jobs and migrants, frequently coloured, filling the lower echelon positions.

The class-division would not last if the children of immigrants up-grade their skills. Unfortunately, the inter-generational up-grade is not occurring.

This has been linked to their poor education and skill-levels. Polynesian children show low achievement in literacy on entering school, and the poor performance continues throughout their schooling, 
as they live in communities and go to schools with fewer resources than mainstream New Zealanders.

Explanations centre around either their poor quality pre-school/ home experience, or the unsuitability of the NZ education system for their needs. Both explanations recognise a cultural mis-match that does not generate economic success for the migrant's children.

The fact that immigration may be fuelling an underclass is of concern given the higher fertility rates of this group. The Ministry of Pacific Island Affairs has forecast that with high fertility and assuming net migration of only 1000 a year, their percent of the total population is expected to increase to 8.3 percent in 2021 and 12.1 percent in 2051. In reality, Pacific Island migration has been much greater than this. For example, in the year 2004/05, over 6,700 were approved for residence from Tonga, Fiji and Samoa, which suggests in the future may have a very large proportion of its population with low productivity.

These poor economic outcomes are linked to other social problems. Pacific people are over-represented in justice statistics with higher rates of conviction and prosecution than the total population. They are more likely to be the victims of violent crime, more likely to need government assistance for housing and income, and have lower life expectancies (Clydesdale, 2008b).

It is difficult to comprehend in retrospect why Dr Clydesdale's findings received such widespread attention, since:

- they consisted of a mere five paragraphs and a table with nine statistics from a 2002 report;

- the first paragraph is a history of Pacific migration and includes some incomplete and inaccurate information;

- the second paragraph selectively quotes from the same 2002 report but omits the more positive conclusion it draws from over 100 pages of data and analysis;

- the third paragraph makes some statements about crime that are unsourced and for which no evidence is provided;

- the fourth paragraph briefly cites two sources to support a conclusion that there is 'a cultural mis-match that does not generate economic success for the migrant's children';

- the fifth paragraph speaks of the possibility of an underclass developing because of high fertility rates and high levels of 
immigration when the Pacific population of New Zealand only increased from 6.5 percent to 6.9 percent from both natural increase and migration between 2001 and 2006; and

- the paper contains little more information about Pacific peoples than was contained in the press release issued by Dr Clydesdale.

\section{Information about Pacific peoples in New Zealand}

There is a range of information readily available from public agencies concerning the economic and social situation of Pacific peoples, including:

- the Pacific Progress Report, published by the Ministry of Pacific Island Affairs in 2002, which provides a useful baseline of information but needs updating in view of the 2006 Census

- Quickstats about Pacific Peoples, recently published by Statistics New Zealand, which contains information from the 2006 Census on demographics, language, religion, education, work, and income

- The Social Report, published by the Ministry of Social Development, which tracks the social wellbeing of Pacific peoples through a range of indicators and includes a comparison with European peoples

- a Pacific Peoples labour market fact sheet, published by the Department of Labour, based on the Household Labour Force Survey

- a fact sheet on Pacific peoples in tertiary education and annual information on the attainment of Pasifika school leavers, published by The Ministry of Education

- an annual review of migration trends, published by the Department of Labour

- an extensive range of other data about Pacific peoples from Statistics New Zealand, and reports from Housing New Zealand, the Ministry of Health and the Victoria University and the Institute of Policy Studies.

The available data generally indicate a trend of improvement rather than deterioration in Pacific peoples' economic and social situation. At the same time Pacific peoples continue to experience significant inequalities and addressing them must remain a priority. 


\section{Conclusion}

It is unlikely that Dr Clydesdale's claims would have sparked such controversy if The Dominion Post had not run the story as its front page lead. Dr Clydesdale had been reported in the media on a number of previous occasions on the same subject, including in The Dominion Post, and his claims attracted very little public attention. The Dominion Post said it published the story because of Clydesdale's status as an academic. They assumed that he was a credible expert whose claims about Pacific peoples would be supported by professional research and analysis. Massey University said that Clydesdale was exercising his academic freedom. Both the Education Act and Massey University's own policies however emphasise that academic freedom entails the observance of the highest ethical and professional standards. The university is publicly accountable for the maintenance of these.

Pacific peoples were angered and dismayed by Dr Clydesdale's claims, their publication on the front page of the Dominion Post, and racially prejudiced responses on talkback radio and the internet. No evidence was provided to support the claim that they were an underclass or a drain on the economy. They suffered disproportionately from the economic and social policies of the 1980s and 1990s. Although they do continue to experience social and economic disadvantage their situation is generally improving and their economic, social and cultural contribution is significant.

The controversy highlighted four intersecting issues:

- the personal responsibility of academics to maintain high standards in the research and publication of their work;

- the responsibility of the media to be accurate and balanced when publishing controversial claims;

- The responsibility and accountability of universities to uphold ethical and professional standards as an integral part of academic freedom; and

- the vulnerability to racial prejudice of distinct population groups that experience social and economic inequality.

These matters deserve continuing discussion in light of the controversy about the publication of Dr Clydesdale's discussion paper. 


\section{Notes}

1. An analysis and schedule of all 216 comments on the Stuff website is contained in the Commission's background document on the media issues relating to Dr Greg Clydesdale's discussion paper, which is available at www.hrc.co.nz .

2. Misrepresenting the Pacific community, tvnz.co.nz/view page/411319/1838364

3 . The press release included the following statement that also became part of the public controversy: 'Dr Clydesdale believes the government fails because it does not recognise the importance of culture. Migrants from Asia and the Pacific perform particularly badly. Education and skills are not always transferable across cultures. NZ employers are also concerned with "team-fit" and the communication skills of their employees. The government seems scared to make a policy change which could open claims of eugenics, but culture is a very real phenomenon with important consequences for outcomes. Migrants suffer from over-education, unemployment and under-employment. On the human level, this means broken dreams and un-met expectations. The cultural issue might not be so pronounced if migration occurs on a smaller scale, as migrants are forced to integrate. However, when immigration occurs on a large scale, migrants are insulated by the host country around them. The government also fails to recognise the time it takes for migrants to contribute fully to the economy. Although migrants from Australia, UK and Ireland were active labour participants very early after arrival immigrants in general require 15-25 years before their income converges with locals.'

4. These included comments on immigration by the co-leader of the Māori Party, Tariana Turia, and the Governor of the Reserve Bank, Alan Bollard in 2007, and the public spotlight on the Pacific Division of the Immigration Service in 2008.

5. gpacts.knowledge-basket.co.nz/gpacts/reprint/text/2006/se/013se161.html

6. www.massey.ac.nz/massey/research/ethics/human-ethics/code/code.cfm

\section{References}

Chalmers, A., and Ling, J. (2008, June 7), Massey faces claims of supporting poor research. Dominion Post, p. 9.

Clydesdale, G. (2008a, May). Discussion paper: New Zealand immigration policy. Retrieved at Pacific Media Watch on 22 April 2009, from kauri.aut.ac.nz:8080/ dspace/handle/123456789/205

Clydesdale, G. (2008b, n.d.). Polynesian immigration fuels underclass. Media release.

Human Rights Commission (2008, August). Pacific peoples in New Zealand. Review of the public controversy about a discussion paper on immigration policy and the economic contribution of Pacific migrants to New Zealand.

Extremes of correctness. (2008, May 28). Editorial. Dominion Post, p. 4.

Island 'underclass' report under way (2008, May 26). Dominion Post, p. 2.

Ling, J. (2008a, May 20). Pacific migrants 'drain on the economy'. Dominion Post, p. 1. 
Ling, J. (2008b, May 29). Economist stands by underclass comments. Dominion Post, p. 7.

Ling, J. (2008c, June 6). Views in PI paper 'academic freedom', Dominion Post, p. 4

Pacific community 'gutted by study' (2008, May 21). Dominion Post.

Tu'itahi, S. (2008, May 27). Massey's Pasifika director says report fails to recognise wider contribution of Pacific people. Massey University media release. Retrieved on 1 June 2008, from www.massey.ac.nz/massey/about-us/news/article. $\mathrm{cfm}$ ?mnarticle=masseys-pasifika-director-says-report-fails-to-recognise-widercontribution-of-pacific-people-27-05-2008

Welham, K. (2008, August 9). Pacific divide. Dominion Post, p. 3.

Joris de Bres is Race Relations Commissioner with the New Zealand Human Rights Commission. This article is extracted by him for Pacific Journalism Review from the 2008 commission report 'Pacific Peoples in New Zealand: Review of the public controversy about a discussion paper on immigration policy and the economic contribution of Pacific migrants to New Zealand'. JorisdB@hrc.co.nz

\section{Fijian Studies}

A Journal of Contemporary Fiji

\section{Volume 6 Number 1 \& 2 \\ Editors: Shailendra Singh and Biman Prasad}

\section{Media, Democracy and Development in Fifi: The last 20 years}

This forthcoming special edition looks at the mainstream news media in Fiji. It covers the last 20 years, a turbulent period in Fiji's history scarred by four coups in May and September of 1987, May 2000 and December 2006.The coups have, cumulatively, stunted progress and brought Fiji to its knees. They caused political and social chaos, heightened racial tensions and crippled the economy. The coups can also be blamed for an inexorable decline in living standards. Articles are contributed by leading journalists, academics and commentators.

\section{Published by the Fiji Institute of Applied Studies (FIAS) PO Box 7850, Lautoka, Fiji Islands www.fijianstudies.org}

